\title{
Co-infection of intestinal parasites and Helicobacter pylori among upper gastrointestinal symptomatic adult patients attending Mekanesalem Hospital, northeast Ethiopia
}

\author{
Abdurahaman Seid*, Zemenu Tamir, Brhanu Kasanew and Moges Senbetay
}

\begin{abstract}
Objective: Intestinal parasites and H. pylori are well-known for their high prevalence worldwide. Thus, the objective of this study waste assess risk factors and co-infection of intestinal parasites and $\mathrm{H}$. pylori among adult patients with upper gastrointestinal complaints. A hospital-based cross sectional study was conducted among 363 consecutive adult patients from December 10, 2015 to February 30,2016. Stool and venous blood were collected for analysis of Intestinal parasites and H. pylori infection, respectively. Data was analyzed using SPSS version 16 and logistic regression analysis was carried out to assess predictors of co-infection. A $p \leq 0.05$ was considered as statistically significant.

Results: Helicobacter pylori lgG and intestinal parasites were detected in $70.25-38.3 \%$ of participants, respectively while G. lamblia accounted 22.3\%. G. lamblia prevalence was significantly higher among H. pylori infected participants (COR: 2.76; 95\% Cl: 1.46-5.23), but E. hystolytica/dispar infection didn't show significant variation $(p=0.15)$. H. pylori and intestinal parasites concomitant co-infection was associated with male sex (AOR: 1.61; 95\% Cl: 1.01-2.56), consumption of river water (AOR: 1.85; 95\% Cl: 1.11-3.07) and ground/spring water (AOR: 4.10; 95\% Cl: 1.97-8.52). Thus, besides H. pylori investigation, upper gastrointestinal symptomatic patients should be screened for G. lamblia infection and other intestinal parasites.
\end{abstract}

Keywords: Co-infection, H. pylori, G. lamblia, Ethiopia

\section{Introduction}

Gastrointestinal symptoms are highly prevalent in the general population. Dyspepsia is the most common upper gastrointestinal symptom complex [1-3] with $25 \%$ of the general population suffering from dyspeptic symptoms $[4,5]$. The causes of dyspepsia remain uncertain and are likely to be infectious and non-infectious agents. Helicobacter pylori (H. pylori), Giardia lamblia (G. lamblia)] and coeliac disease are common causes of dyspepsia [6]. Recently, polymicrobial causes of upper gastrointestinal disorders have gained tremendous clinical significance,

*Correspondence: gechdk2000@yahoo.com Po. Box 1145, Dessie, Ethiopia and the importance of synergism has been identified as significant contributor of dyspepsia [7].

It is estimated that $H$. pylori infects more than $50 \%$ of the world population [8] with highest burden among developing countries like those in Africa [9]. G. lamblia has also a worldwide distribution affecting approximately 200 million people globally with 500,000 new cases per year [10]. Besides similar mode of transmission and strong co-relation to socioeconomic levels [11], urease production by $H$. pylori helps intestinal parasites and bacteria to easily cross the stomach's acid environment [12].

Besides $H$. pylori infection, G. lamblia has been found to trigger symptoms of gastrointestinal disorders [13, 
14] with dyspepsia reported to be the main symptoms of gastric giardiasis [15]. Similarly, 30\% and $15.8-44 \%$ of $H$. pylori and G. lamblia infection, respectively was reported among patients with dyspepsia $[6,11]$. Children with gastric complaints showed $65,10-25 \%$ of $H$. pylori infection, giardiasis and amoebiasis, respectively [16]. In different parts of the world, a potential association between intestinal protozoans and $H$. pylori infection was documented $[6,17,18]$ with $75 \%$ prevalence of $H$. pylori infection among patients with gastric giardiasis [16]. This suggests that health care professionals should be aware of gastric giardiasis as a possible cause of dyspepsia.

In Ethiopia, many studies reported high prevalence of H. pylori infection among dyspeptic patients [19-23], but information about rate of intestinal parasites infection is limited. Besides H. pylori infection, it is necessary to assess intestinal parasite infection status of dyspeptic patients to improve their clinical outcome. Therefore, the aim of this study was to assess concomitant co-infection of intestinal parasites and $H$. pylori, and associated risk factors of adult upper gastrointestinal symptomatic patients at Mekanesalem Hospital.

\section{Main text \\ Methods \\ Study patients and setting}

This cross-sectional study was conducted at Mekanasalem Hospital from December 10, 2015 to February 30, 2016. It is located in South Wollo zone, Amhara region, northeast Ethiopia. It is the only Hospital in the study area, with 200 beds and different units of both inpatient and outpatients services to the community. The minimum sample size was determined to be 384 by taking $5 \%$ marginal error, $95 \% \mathrm{CI}$, and $50 \%$ prevalence since there was no previous study on the current issue. The study population consisted of adult consecutive outpatients with complaints of one or more upper gastrointestinal symptoms with clinical indications of $H$. pylori infection.

\section{Inclusion and exclusion criteria}

Participants who had at least one of the following upper gastrointestinal complaints such as upper abdominal pain, abdominal bloating, nausea, vomiting, early satiation, post prandial fullness, heartburn, regurgitation, epigastric pain/burning, belching and being volunteer to participate were included. However, patients who were on antibiotic and anti-parasite drugs for 1 week prior to the study involvement, and those with mental problems and patients below 18 years old were excluded.

\section{Data collection}

Each study participants were asked to respond to a questionnaire containing sex, age, residence, marital status, education, occupation, and environmental conditions such as water supply and availability of toilet. About $5 \mathrm{ml}$ of venous blood was collected from each participant and serum was separated for serological testing. Thereafter, each participant was given a pre-labeled clean and dry plastic container to collect fresh stool specimen so as to check for intestinal parasites.

\section{Clinical specimen analysis}

All collected stool samples were screened for intestinal parasites by using direct wet mount using $0.85 \%$ sodium chloride solution as recommended by standard guideline [24]. The blood samples were examined serologically for $H$. pylori immunoglobulin G (IgG) antibodies using immune chromatographic rapid test kits (dBest H. pylori test kit, Zhejiang, China), which is nationally approved and used for serological diagnosis of $H$. pylori infection. The manufacturers' instruction was strictly followed for diagnosis of $H$. pylori infection.

\section{Statistical analysis}

Statistical analysis was performed with SPSS version 16.0. For the descriptive data, frequencies and percentages were used to describe the characteristics of the participants. To assess the association between dependent and independent variables, logistic regression analysis was used. Odds ratios (OR) and 95\% confidence intervals (CI) were used to indicate association of the variables. A $p \leq 0.05$ was considered statistically significant.

\section{Ethics approval and consent to participate}

Research Ethical approval was obtained from the research ethics committee of Wollo University, college of medicine and health sciences, and permission letters was obtained from the hospital management committee. Before commencement of data collection the purpose of the study was explained to the participants and all of them provided written informed consent. Intestinal parasite and $H$. pylori screening was performed free of charge, and those found to have infection were managed by physicians.

\section{Results \\ Socio-demographic characteristics}

During the study period a total of 363 (57.3\% females) with upper gastrointestinal symptomatic adults who fulfilled the inclusion criteria were included in the analysis. The age of participants ranged from 18 to 85 years with a mean $( \pm$ SD) of $39.11 \pm 15.38$ years. Majorities, $38.3 \%$, of the participants do not have formal education and $42.1 \%$ were farmer. Two hundred eight (57.3\%) of total participants were rural residents, and $61.4 \%$ of participants had used tap water for their daily consumption. The 
socio-demographic characteristic of study participants is summarized in Table 1.

\section{Pylori and intestinal parasites co-infection}

Among 363 participants, $H$. pylori IgG and intestinal parasite (IP) were detected in 225 (70.25\%) and 139 (38.3\%) participants, respectively. G. lamblia accounted $22.3 \%$ of isolated parasites. Higher proportion of IP (44.3\%) was detected among $H$. pylori infected participants. Univariate analysis showed statistically significant association between G. lamblia and $H$. pylori infection $(\mathrm{COR}=2.76$; 95\% CI: 1.46-5.23). However, no significant association observed between E. hystolytica/diaper and H. pylori infection as shown in Table 2.

Univariate analysis showed statistically significant association between gender, residence, type of occupation, educational level, availability of toilet in the home/ village, type of water source for daily consumption and H. pylori-IP co-infection. However, clearing the possible confounding factors, a multiple logistic regression model showed statistical significant association between male gender (AOR: 1.61; 95\% CI: 1.01-2.56), river water consumption (AOR: 1.85; 95\% CI: 1.11-3.07), ground/spring water consumption (AOR:4.10; 95\% CI: 1.97-8.52) and H. pylori-IP co-infection (Table 3).

\section{Discussion}

Giardia lamblia, E. hystolytica/dispar and H. pylori are considered the most common infectious agents affecting human beings in developing countries [25]. In our study, intestinal parasites were detected in $38.3 \%$ of upper gastrointestinal symptomatic patients with G. lamblia (22.3\%) being the most prevalent. A similar study conducted in Mexico showed higher (48.4\%) prevalence of IP infection with $E$. histolytica/dispar being the dominant (21.5\%) parasite [26]. However, our result is comparable to a study conducted in Sudan where $22 \%$ of G. lamblia was detected among patients with gastrointestinal disorder [27].

In this study, high prevalence of IP (44.3\%) was observed among $H$. pylori infected individuals compared to uninfected participants, which is in agreement to a recent report from Ethiopia where IP was significantly associated with $H$. pylori infection [20]. This is due to urease production by $H$. pylori that converts urea of the stomach wall to ammonia resulting in increment in stomach $\mathrm{pH}[28,29]$ and allowing intestinal parasites to cross easily and reach to intestine. The possible similar routes of transmission such as the fecal-oral route could also explain the observed high prevalence of IP among $H$. pylori infected participants in our study.

Even though higher proportion of E. histolytica/dispar was observed among $H$. pylori infected than uninfected
Table 1 Socio-demographic characteristics of study participants attending at Mekanesalem Hospital from December 10, 2015 to February30, $2016(\mathrm{~N}=363)$

\begin{tabular}{|c|c|c|}
\hline Variable & Frequency & $\%$ \\
\hline \multicolumn{3}{|l|}{ Sex } \\
\hline Male & 155 & 42.7 \\
\hline Female & 208 & 57.3 \\
\hline \multicolumn{3}{|l|}{ Age in years } \\
\hline$\leq 20$ & 36 & 9.9 \\
\hline $21-30$ & 103 & 28.4 \\
\hline $31-40$ & 84 & 23.1 \\
\hline $41-50$ & 63 & 17.4 \\
\hline$>50$ & 77 & 21.2 \\
\hline \multicolumn{3}{|l|}{ Residence } \\
\hline Urban & 155 & 42.7 \\
\hline Rural & 208 & 57.3 \\
\hline \multicolumn{3}{|l|}{ Marital status } \\
\hline With partner & 234 & 64.5 \\
\hline Without partner & 129 & 35.5 \\
\hline \multicolumn{3}{|l|}{ Education } \\
\hline Illiterate & 139 & 38.3 \\
\hline Primary school (1-8 grade) & 72 & 19.8 \\
\hline Secondary school (9-12 grade) & 64 & 17.6 \\
\hline College and above & 88 & 24.2 \\
\hline \multicolumn{3}{|l|}{ Occupation } \\
\hline Farmer & 153 & 42.1 \\
\hline Student & 71 & 19.6 \\
\hline House wife & 40 & 11 \\
\hline Government employee & 68 & 18.7 \\
\hline Others & 31 & 8.5 \\
\hline \multicolumn{3}{|l|}{ Drinking water } \\
\hline Tap water & 223 & 61.4 \\
\hline River & 104 & 28.7 \\
\hline Ground/spring & 36 & 9.9 \\
\hline \multicolumn{3}{|l|}{ Availability of toilet } \\
\hline No & 68 & 18.7 \\
\hline Yes & 295 & 81.3 \\
\hline
\end{tabular}

participants, this is not statistically significant. Similar to our result, Moreira et al. showed no significant association between $E$. histolytica infection and $H$. pylori seropositivity [30]. However, Torres et al. showed significantly lower prevalence of $H$. pylori infection among adults carrying $E$. histolytica than without $E$. histolytica [26]. However, this needs well designed cohort type research to ascertain the association.

In our study, we found a significantly higher proportion of giardiasis in participants that also had H. pylori infection as shown in Table 2. Our result is comparable to other studies conducted elsewhere in the world with strong correlation of concomitant G. intestinalis and $H$. pylori infections [30-33]. Recently, Zylberberg et al. in 
Table 2 Prevalence of $\boldsymbol{H}$. pylori and intestinal parasites among study participants attending at Mekanesalem Hospital from December 10, 2015-February 30, 2016

\begin{tabular}{lclcl}
\hline & Total (\%) & \multicolumn{2}{l}{ H. pylori infection } & COR (95\% Cl) \\
\cline { 3 - 5 } & & No, no (\%) & Yes, no (\%) & \\
\hline Intestinal parasite & & & & \\
No parasite & $224(61.7)$ & $82(75.9)$ & $142(55.7)$ & 1 \\
G. lamblia & $81(22.3)$ & $14(13)$ & $67(26.3)$ & $2.76(1.46-5.23)$ \\
E. hystolytica & $47(12.9)$ & $12(11.1)$ & $35(13.7)$ & $1.68(0.83-3.43)$ \\
A. lumbricoids & $4(1.1)$ & - & $4(1.6)$ & $0.002^{*}$ \\
E. vermicularis & $7(1.9)$ & - & $7(2.7)$ & 0.15 \\
Total & $363(100)$ & $108(100)$ & $255(100)$ & \\
\hline
\end{tabular}

* Significant

Table 3 Regression analysis showing factors associated with $H$. pylori-intestinal parasites co-infection

\begin{tabular}{|c|c|c|c|c|c|}
\hline Variables & $\mathrm{n}$ & $\begin{array}{l}\text { Co-infection } \\
\text { Yes (\%) }\end{array}$ & COR $(95 \% \mathrm{Cl})$ & AOR $(95 \% \mathrm{CI})$ & p value \\
\hline \multicolumn{6}{|l|}{ Sex } \\
\hline Female & 208 & $55(26.4)$ & 1 & 1 & \\
\hline Male & 155 & $57(36.8)$ & $1.62(1.03-2.54)$ & $1.61(1.01-2.56)$ & $0.044^{*}$ \\
\hline \multicolumn{6}{|l|}{ Residence } \\
\hline Urban & 155 & $33(21.3)$ & 1 & & \\
\hline Rural & 208 & $79(38.0)$ & $2.26(1.41-3.64)$ & - & \\
\hline \multicolumn{6}{|l|}{ Marital status } \\
\hline Without partner & 129 & 45 (34.9) & 1 & - & \\
\hline With partner & 234 & $67(28.6)$ & $0.75(0.47-1.19)$ & & \\
\hline Gov't employee & 68 & $14(20.6)$ & 1 & & \\
\hline \multicolumn{6}{|l|}{ Occupation } \\
\hline Farmer & 153 & $58(37.9)$ & $2.36(1.20-4.61)$ & - & \\
\hline Student & 71 & $26(36.6)$ & $2.23(1.04-4.77)$ & - & \\
\hline House wife & 40 & $10(25.0)$ & $1.29(0.51-3.25)$ & - & \\
\hline Other & 31 & $4(12.9)$ & $0.57(0.17-1.90)$ & - & \\
\hline \multicolumn{6}{|l|}{ Education } \\
\hline Illiterate & 139 & $51(36.7)$ & $2.10(1.14-3.89)$ & - & \\
\hline Primary (1-8) & 72 & $17(23.6)$ & $1.12(0.53-2.36)$ & - & \\
\hline Secondary (9-12) & 64 & $25(39.1)$ & $2.33(1.14-4.76)$ & - & \\
\hline College and above & 88 & $19(21.6)$ & 1 & & \\
\hline \multicolumn{6}{|l|}{ Availability of toilet } \\
\hline Yes & 295 & $78(26.4)$ & 1 & & \\
\hline No & 68 & $34(50)$ & $2.78(1.62-4.78)$ & - & \\
\hline \multicolumn{6}{|l|}{ Drinking water } \\
\hline Tap & 223 & $53(23.8)$ & 1 & 1 & \\
\hline River & 104 & $39(37.5)$ & $1.93(1.17-3.18)$ & $1.85(1.11-3.07)$ & $0.018^{*}$ \\
\hline Ground/spring & 36 & $20(55.6)$ & $4.01(1.94-8.29)$ & $4.10(1.97-8.52)$ & $0.000^{*}$ \\
\hline
\end{tabular}

* Significant

US found that individuals colonized with $H$. pylori are independently associated with giardiasis [34]. A case control study showed no significant difference in $H$. pylori and other IP infection, but the combination of $H$. pylori infection and giardiasis was significantly higher among symptomatic patients compared to controls [18]. 
However, our result is in contrary to study conducted in Sudan with no statistically significant difference of $G$. lamblia-H. pylori co-infection among $H$. pylori infected and uninfected participants [27]. This could be due to less sample size of the Sudan study. Moreover, we investigate $H$. pylori infection using IgG antibody which may not able to detect recent infection. In our study, the large proportion of $H$. pylori and giardia co-infections could be due to the role of urease produced by $H$. pylori. It is found a significant increase in urease activity among coinfected (giardiasis and H. pylori) compared to mono (G. lamblia) infected individuals [35]. But it is still vague whether giardiasis increases the susceptibility to $H$. pylori or not, which warrants further case control cohort and molecular based study.

Our result showed statistical significant association between male gender, river as well as ground/spring water consumption and $H$. pylori-intestinal parasites co-infection. This agrees with study in Egypt as gender is significantly associated with Giardia and $H$. pylori co-infection [31]. Furthermore, community based study is needed in this area to identify and clarify the possible risk factors of co-infection.

\section{Conclusion}

The present study revealed that $38.3-70.2 \%$ of IP and $H$. pylori infection, respectively, with a strong correlation of concomitant G. lamblia and H. pylori infections. Gender and type of drinking water source was significantly associated with intestinal parasites and $H$. pylori concomitant co-infection. The observed association requires further study to investigate the observed relationship in more detail, and explanations of this association are required. Besides H. pylori investigation, screening of G. lamblia infection is recommended for successful management of upper gastrointestinal symptomatic patients.

\section{Limitations}

The results of this study cannot be representative of the general population due to the following limitations:

- The cross-sectional nature of the study has limitation to show real correlation of IP and H. pylori infection.

- H. pylori IgG detection may overestimate the prevalence of $H$. pylori infection.

- Direct wet mount preparation may under estimate the prevalence of IP.

- Prevalence of H. pylori and intestinal parasites coinfection could not be representative of the general population since only upper gastrointestinal symptomatic patients were included in the study.

\section{Abbreviations}

AOR: adjusted odds ratio; COR: crude odds ratio; IgG: immunoglobulin G; IP: intestinal parasite; OR: odds ratio.

\section{Authors' contributions}

AS: performed the design of the study, data acquisition and management, study supervision, analysis, interpretation of data and manuscript preparation. ZT: study design, supervision, data acquisition, critical review of the manuscript; BK: study design, acquisition of data; MS: study design, acquisition of data. All authors have edited the final manuscript for publication. All authors read and approved the final manuscript.

\section{Acknowledgements}

We would like to thank all the study participants, the data collectors and the laboratory technicians who participated in the research work. Our special thanks also go to Mekanesalem Hospital administration for its unreserved support during the data collection.

\section{Competing interests}

The authors declare that they have no competing interests.

\section{Availability of data and materials}

The authors confirm that all data underlying the findings are fully available without restriction. The corresponding author is responsible to be contacted and justify any question regarding to the result. All relevant data are within the manuscript.

\section{Consent for publication}

Not applicable.

\section{Ethics approval and consent to participate}

Research ethical approval was obtained from the research ethics committee of Wollo University, college of medicine and health sciences, and permission letters was obtained from the hospital management committee. Before commencement of data collection the purpose of the study was explained to the participants and all of them provided written informed consent. Intestinal parasite and $H$. pylori screening was performed free of charge, and those found to have infection were managed by physicians.

\section{Funding}

This research received no specific grant from any funding agency in the public, commercial, or not-for-profit sectors.

\section{Publisher's Note}

Springer Nature remains neutral with regard to jurisdictional claims in published maps and institutional affiliations.

Received: 30 October 2017 Accepted: 10 February 2018 Published online: 20 February 2018

\section{References}

1. Wallander MA, Johansson S, Ruigomez A, Garcia Rodriguez LA, Jones R. Dyspepsia in general practice: incidence, risk factors, comorbidity and mortality. Fam Pract. 2007;24:403-11.

2. Tack J, Talley NJ, Camilleri M, Holtmann G, Malagelada JR, Stanghellini V. Functional gastroduodenal disorders. Gastroenterology. 2006;130:1466-79.

3. Tepeš B. Subgroups of dyspepsia. In: Duvnjak M, editor. Dyspepsia in clinical practice. Berlin: Springer; 2011. p. 9-18.

4. Hasan M. Dyspepsia in primary care practice in Bangladesh. Bangladesh Med J. 2013;42(2):63-9.

5. Yazdanpanah K, Moghimi N, Yousefinejad V, Ghaderi E, Azizi A, Nazem SF. Dyspepsia prevalence in general population aged over 20 in the west part of Iran. J Pak Med Assoc. 2012;62(7):672-6.

6. Fouad SA, Esmat S, BasyoniMaha MA, Salah Farhan M, Kobaisi MH. Molecular identification of Giardia intestinalis in patients with Dyspepsia. Digestion. 2014;90:63-71. https://doi.org/10.1159/000362644. 
7. Brogden KA, Guthmiller JM, Taylor CE. Human polymicrobial infections. Lancet. 2005;365:253-5.

8. World Gastroenterology Organization Global Guideline. Helicobacter pylori in developing countries. J Dig Dis. 2011;12:319-26.

9. Olokoba A, Gashau W, Bwala S, Adamu A, Salawu FK. Helicobacter pylori infection in Nigerians with dyspepsia. Ghana Med J. 2013;47(2):79-81.

10. Ivanov Al. Giardia and giardiasis. Bulgarian J Vet Med. 2010;13(2):65-80.

11. Yakoob J, Jafari W, Abid S, Tafari N, Hamid S, Shah HA, Rizvi L, Islam M, Shaikh H. Giardiasis in patient with dyspeptic symptoms. World J Gastra enteral. 2005;11(42):6667-66705.

12. David TJ, William AP, Markell EK, Vege S. Medical parasitology, vol. 9. New York: Saunders Elsevier; 2006.

13. Hanevik K, Dizdar V, Langeland N, Hausken T. Development of functional gastrointestinal disorders after Giardia lamblia infection. BMC Gastroenterol. 2009;9:27. https://doi.org/10.1186/1471-230X-9-27.

14. Guarnieri G, Spiniello E. Giardia lamblia infection in patients with irritable bowel syndrome and dyspepsia: a prospective study. World J Gastroenterol. 2006;12:1941-4.

15. Sanad MM, Darwish RA, Nasr ME, El-Gammal NE, Emara MW. Giardia lamblia and chronic gastritis. J Egypt Soc Parasitol. 1996:26(2):481-95.

16. Bin Mohanna MA, Al-Zubairi LM, Sallam AK. Prevalence of Helicobacter pylori and parasites in symptomatic children examined for Helicobacter pylori antibodies, antigens, and parasites in Yemen. Saudi Med J. 2014;35(11):1408-11.

17. Kazemian H, Shavalipour A, Mohebi R, Ghafurian S, Aslani S, Maleki A, Kardan J, Hiedari H, Sadeghifard N. Estimation of the parasitic infection prevalence in children with Helicobacter pylori infection in llam City (2012-2013). Arch Pediatr Infect Dis. 2014. https://doi.org/10.5812/pedin fect.15294.

18. Zeyrek D, Zeyrek F, Cakmak A, Cekin A. Association of Helicobacter pylori and giardiasis in children with recurrent abdominal pain. Türkiye Parazitol Derg. 2008;32(1):4-7.

19. Asrat D, Nilsson I, Mengistu Y, et al. Prevalence of Helicobacter pylori infection among adult dyspeptic patients in Ethiopia. Trop Med Parasitol. 2004;98:181-9.

20. Kibru D, Gelaw B, Alemu A, Addis Z. Helicobacter pylori infection and its association with anemia among adult dyspeptic patients attending Butajira Hospital, Ethiopia. BMC Infect Dis. 2014;14:656. https://doi. org/10.1186/s12879-014-0656-3.

21. Tesfahun T, Yohannes M, Kassu D, Daniel A. Seroprevalence of Helicobacter pylori infection in and its relationship with $\mathrm{ABO}$ blood groups. Ethiop J Health Dev. 2005:19(1):55-9.

22. Moges F, Kassu A, Mengestu G, et al. Seroprevalence in dyspeptic patients and its relationship with HIV infection, $\mathrm{ABO}$ blood group and life style in a university hospital, north west Ethiopia. World J Gastroenterol. 2006;12:1957-61.

23. Wubejig A, Mulugeta K, Bayeh A. Prevalence and risk factors of H. pylori from dyspeptic patients in northwest Ethiopia: a hospital based crosssectional study. Asian Pac J Cancer Prev. 2014;15(11):55-9.

24. Chesbrough M. Medical laboratory manual for tropical countries. Vol. II: Microbiology tropical health. Technology/butter worths and co. Ltd: Cambridge/Sevenaks; 2006.

25. Sabet EA, El-hadi HA, Mohamed DS, Sheneef A, Fattouh M, Esmat MM. "Gastritis; Helicobacter pylori or Giardia lamblia infection or both". Egyptian J Med Microbiol. 2009;18(4):165-78.

26. Torres J, Perez Perez G, Ximenez C, Muñoz L, Camorlinga-Ponce M, Ramos F, Gomez A, Muñoz O. The association of intestinal parasitosis and H. Pylori infection in children and adults from a Mexican community with high prevalence of parasitosis. Helicobacter. 2003;8(3):179-85.

27. Ahmed NFM, Elfaki TEM, Elsayid M. Prevalence rate of Giardia lamblia/Helicobacter Pylori co-infections in Khartoum State, Sudan. Int $J$ Sci Technol Res. 2016;5(3):181-90.

28. Kuster JG, Vanviret AH, Kulpers EJ. Pathogenisis of H. pylori infections. Clin Microbiol Rev. 2006:19(3):449-90.

29. Boyanova L, Mitov I, Vladimirov B. Epidemiology of H. pylori infection. USA Caister Academic press Univ of Kanasas; 2011. p. 84-94.

30. Moreira ED Jr, Nassri VB, Santos RS, Matos JF, De Carvalho WA, Silvani CS, Sant'Ana CS. Association of Helicobacter pylori infection and giardiasis: results from a study of surrogate markers for fecal exposure among children. World J Gastroenterol. 2005;11(18):2759-63.

31. El-badry AA, Ghieth M, Ahmed DA, Ismail MA. Giardia intestinalis and helicobacter pylori co-infection: estimated risks and predictive factors in egypt. J Egypt Soc Parasitol. 2017;47(1):19-24.

32. Ankarklev J, Hestvik E, Lebbad M, Lindh J, Kaddu-Mulindwa DH, et al. Common coinfections of Giardia intestinalis and Helicobacter pylori in non-symptomatic Ugandan children. PLoS Negl Trop Dis. 2012;6(8):e1780 https://doi.org/10.1371/journal.pntd.0001780.

33. Dogliani C, De Boni M, Cielo R, Laurino L, Pelosio P, Braidotti P, Viale G. Gastric giardiasis. J Clin Pathol. 1992;45(11):964-7.

34. Zylberberg HM, Green PH, Turner KO, Genta RM, Lebwohl B. Prevalence and predictors of giardia in the united states. Dig Dis Sci. 2017:62(2):432-40.

35. Abou El-Hoda MM, Osman HM, Rasha MM, Douidar NL, Enany AY. Impact of Helicobacter pylori infection on the activities of urease and lipase enzymes in patients with giardiasis. J Egypt Public Health Assoc. 2007;82(3-4):273-82.

\section{Submit your next manuscript to BioMed Central and we will help you at every step:}

- We accept pre-submission inquiries

- Our selector tool helps you to find the most relevant journal

- We provide round the clock customer support

- Convenient online submission

- Thorough peer review

- Inclusion in PubMed and all major indexing services

- Maximum visibility for your research

Submit your manuscript at www.biomedcentral.com/submit
BioMed Central 